\title{
Enzymatic Pretreatment of Some Lignocellulosic Materials for Biofuel Production
}

R.M.El-Meihy, A.A. Salem, H.M.Abdel-Rahman and N.M.Ashry

Agric. Microbiology Dept., Faculty of Agriculture, Moshtohor, Benha Univ., Egypt

E-Mail: rashaelmehy@fagr.bu.edu.eg

\section{Introduction}

It is known that the world will face in the next few years a serious problem, fuel deficiency is a global issue due to exhaustion of fossil fuel and growing climate change and the depletion of nonrenewable energy sources and thus necessitated thinking in finding alternative sources of energy and at the same time, low cost and cover the growing needs of energy sources [1].

In order to overcome this issue, different types of techniques have been invented for the possible conversion of cellulosic waste materials into glucose for the ethanol production, as an alternative way for fuel conservation [2]. The bioconversion of lignocellulosic materials to bioethanol produces high yield of glucose after hydrolysis.

The utilization of the lignocellulosic materials for the conversion of the biofuel involves only low cost [3]. Lignocellulose, the most abundant organic matter in the earth, can be utilized to produce various renewable fuels [4]. For the digestion of these materials into glucose, many methods have been used such as thermal pretreatments, chemical pretreatments, biological pretreatments and enzymatic pretreatments [5].

Cellulolytic and hemicellulolytic enzymes are able to increase monosugars from the digestion of lignocellulose [6]. For this purpose, bacteria, actinobacteria and fungi that produce cellulolytic enzymes are employed.

Agricultural wastes represent 5\% of the volume of environmental pollutants. Egypt has an abundance of agricultural wastes, which still have negative effects on the environment and does not make use of them and that can bring additional income to the farmer and at the same time can be faded damage these residues utilizing it as one of the energy sources renewable economic. Liquid biofuels include bioalcohols, such as ethanol and butanol, and biodiesel.

Ethanol is the most important liquid biofuel of today. Bioalcohols are manufactured in fermentation processes, in which microbial biocatalysts, yeasts or bacteria, convert sugars to alcohols. The ethanol that is used today is mainly manufactured from lignocelluloses materials.

However, very large-scale use of bioalcohols in the energy sector will require production from lignocellulosic feedstocks [7]. Bioethanol can be used as a transportation fuel instead of fossil fuels which are responsible for climate changes, such as: a) Global warming, that contribute to destructive natural disasters (flood, drought, relentless snowfall, etc.). b) Urban air pollution, which one of the problems humanity has been facing in recent years.

Bioethanol is producible from a variety of feedstocks: such as corn grains, sugar cane and wheat. Moreover, bioethanol can be produced using abundant and renewable biomass: such as agricultural residues, cellulosic wastes and industrial wastes, instead of exhaustible resources.

\section{Review of literature}

The use of microorganisms or their enzymes for the conversion of lignocellulose into simple carbohydrates is receiving increased attention. This is the result of growing concern over the accumulation of wastes, and our awareness of the vast quantities of residues which result from agricultural operations and the manufacture of wood products. Lignocellulose is converted to glucose and biofuels by a multistep process that includes pretreatment, enzymatic hydrolysis, and fermentation [8]. Plant biomass contains large amounts of cellulose and other polysaccharides that can be hydrolyzed to glucose and various other simple sugars for subsequent fermentation to fuel ethanol or used in the production of other industrial chemicals. In nature, the biodegradation of plant biomass is a slow process because lignin and substrate crystallinity greatly restrict the access of hydrolytic enzymes to the polysaccharide components. However, raw biomass can be pretreated and partially fractionated, using processes that typically involve elevated temperature and pressure combined with acid or base catalysis, to yield lignocellulosic materials that are much more susceptible to enzyme attack [9], and [10]. Corn stover or cereal stalks, purposegrown crops like switch grass or hybrid poplar, and softwoods such as spruce and pine from boreal forests show significant quantitative and qualitative differences in their non-cellulosic polysaccharide components [11]. Further differences in composition are introduced according to the pretreatment technology employed. Therefore, it has been suggested that enzyme mixtures could be customized for particular feed stocks and pretreatments in order to optimize hydrolysis.

Pretreatment effects on the enzymatic hydrolysis of lignocellulose producing reducing sugars as glucose and xylose. Hot water pretreatment enhances the enzyme digestibility of corn stover with about a 4 folds increase in glucose conversion over the same time period. Moreover, pretreatment is an important and necessary step that 
opens up the tightly structured cell wall, thereby, allowing carbohydrolytic enzymes access to hemicellulose [8] and [12].

\subsection{Lignocellulose structure}

\subsubsection{Cellulose and its structure}

Cellulose, a principle component of all plant materials, is considered one of the most abundant renewable resources in the world. An estimated synthesis rate of cellulose is approximately $4 \times 10^{10}$ tons per year. Although it is the most promising renewable energy source to overcome the problems of energy resource, chemicals and food in the future, its enormous potential was recognized only after the cellulose degrading enzymes or cellulases had been identified [13]. Cellulose is made of linked glucose molecules connected by $\beta-1,4$ bonds Fig(1) Cellulose is regarded as a valuable resource largely because it can be decomposed into soluble cellobiose and glucose sugars when $\beta$ bonds are broken [14].
This process is called cellulose hydrolysis. Cellulose hydrolysis occurs naturally in soils, sediments, aquatic environments, and in the digestive tracts of animals by microorganisms capable of producing cellulase enzymes [15]. Cellulose is chemically simple because it contains simple repeating units of glucose, but has a complex structure because of the long chains of glucose subunits joined together by $\beta-1,4$ linkages.

Cellulose is stabilized by some interactions; these stabilizing factors are weak individually but collectively form strong bonds. The chains are in layers held jointly by van der Waals forces and hydrogen-bonds (intramolecular and intermolecular).

About thirty individual cellulose molecules are arranged into units called protofibrils, which are further arranged into larger units called microfibrils [16].

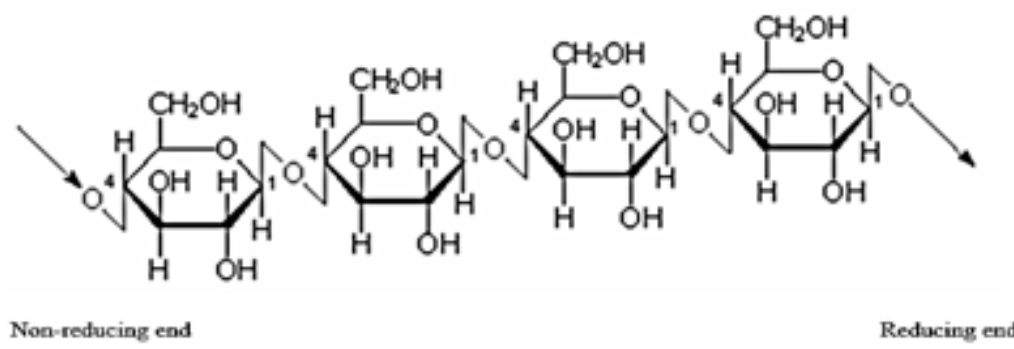

Fig (1) Diagram showing the structural formula and $\_\beta$-1,4-linkages in a cellulose chain

\subsubsection{Hemicellulose and its structure}

Hemicellulose is the second most abundant renewable product and component from $25-35 \%$ of lignocellulosic products. Hemicelluloses are heterogeneous polymers built up by pentoses (Dxylose, D-arabinose), hexoses (D-mannose, Dglucose, D-galactose) and sugar acids. Hemicelluloses in hardwood contained mainly xylans, while in softwood glucomannans are most common [17]. Hemicellulose consists of several different sugar units and substituted side chains in the form of a low molecular weight linear or branched polymer.

This polymer is more soluble than cellulose with a degree of polymerization of less than 200 . Hemicelluloses are named according to their main sugar residues in the backbone. Xylans, consisting of D-xylose units, and glucomannans, consisting of D-glucose and D-mannose units contribute to the main hemicelluloses in hardwoods and softwoods, respectively.

Branched polymers contain neutral and/or acidic side groups. These groups render hemicelluloses noncrystalline or poorly crystalline, so that they exist more like a gel than as oriented fibres. Hemicelluloses form a matrix together with pectins and proteins in primary plant cell walls and with lignin in secondary cell walls.

Covalent hemicellulose-lignin bonds involving ester or ether linkages form lignin-carbohydratecomplexes (LCCs) [18].

Hemicelluloses can be included within and between crystalline cellulose domains during the synthesis of cellulose microfibrils. The relationship between cellulose and hemicellulose in the cell walls of higher plants may be extremely intimate, so it is possible that molecules at the hemicellulose boundaries and those within the domains of crystalline cellulose require different enzymes for efficient hydrolysis [19]. Xylan, the second most abundant polysaccharide and a major component in plant cell wall consists of $\beta-1,4$ linked xylopyranosyl residues [17].

The plant cell wall is a composite material in which cellulose, hemicellulose (mainly xylan) and lignin are closely associated. Three major constituents Fig(2) of wood are cellulose (38-50\%), hemicellulose (23-32\%), a group of carbohydrates in which xylan forms the major class, and lignin $(15-25 \%)$.

In addition, xylan is a heteropolysaccharide containing substituent groups of acetyl, 4-O- 
methyl-D-glucuronosyl and $\beta$-arabinofuranosyl residues linked to the backbone of $\beta$-1,4-linked xylopyranose units and has binding properties mediated by covalent and non-covalent interactions with lignin, cellulose and other polymers.

Lignin is bound to xylans by an ester linkage to 4-O-methyl-D-glucuronic acid residues [20].

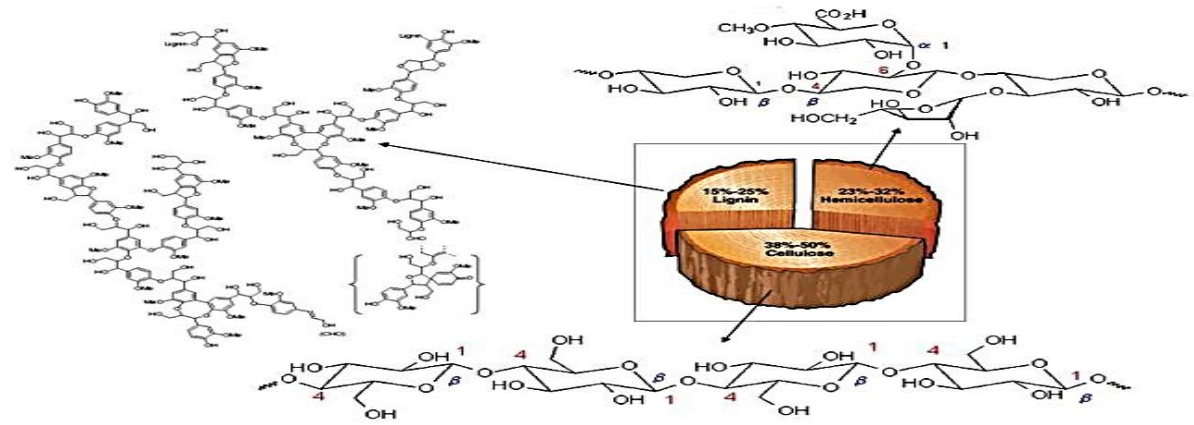

Fig (2) The major constituents of wood

\subsubsection{Lignin and its structure}

Lignin is a branched polymer of substituted phenylpropane units joined by carbon and ether linkages. Biosynthesis of lignin formation proceeds via polymerisation of the free radical forms of precursors, i.e. the monolignols p-coumaryl, coniferyl and sinapyl alcohol.

In the final polymer they form $p$ hydroxyphenyl-, guaiacyl-, and syringyl type units, respectively. Plant laccases and peroxidases catalyse the generation of radical formations. It seems plausible that lignin polymerization pattern and assembly is guided by the orientation of cellulose and the structure of hemicelluloses.

The major linkage in lignin, the arylglycerolßaryl ether substructure, comprises about half of the total interunit linkages [21]. Lignin is a threedimensional polymer found abundantly in wood and plant tissue. It is composed of phenylpropanoid units inter connected by stable C-C and C-O bonds Fig(3).

The heterogeneity and complexity of its structure confers resistance to microbial attack. However, lignin can be degraded slowly in nature, mainly by white-rot fungi, and this has considerable impact in forestry and agriculture.
Lignin biodegradation by white-rot fungi is an oxidative process in which $\mathrm{H}_{2} \mathrm{O}_{2}$ plays an important role [22].

The removal of lignin improves hydrolysis of cellulosic material as it creates additional surface area for enzyme adsorption on the cellulosic substrates. Lignins are high-molecular weight, insoluble plant polymers, which have complex and variable structures.

They are composed essentially of many methoxylated derivatives of benzene (phenylpropanoid alcohols, also called monolignols), especially coniferyl, sinapyl, and coumaryl alcohols, the proportions of these three differ between angiosperms and gymnosperms, and between different plants.

A model suggesting that monolignols are assembled at random to produce a complex polymer that is highly cross linked in three dimensions held sway for many years but is now giving way to the idea that lignins have specific sequences of monolignols that suit the lignin to different functions in the plant cell wall, and there are only a few native lignin primary structures.

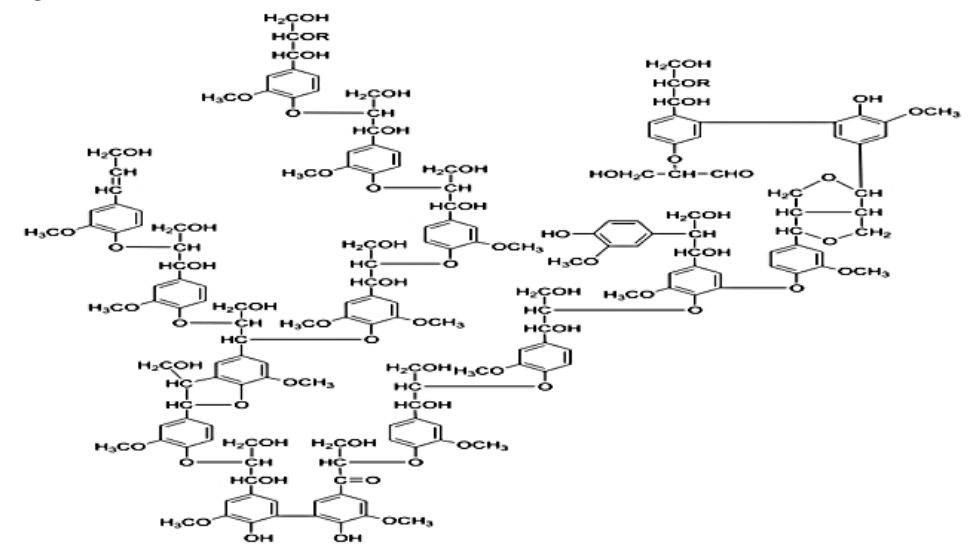

Fig (3) Lignin molecule structure 
2.2 Enzymes required for lignocellulose degradation

\subsubsection{Enzymes required for cellulose degradation}

As a result of the insolubility and heterogeneity of native cellulose, it is recalcitrant to enzymatic hydrolysis. The degradation of crystalline cellulose is a complex process requiring the participation of many enzymes.

Cellulases are the enzymes responsible for the cleavage of the $\beta$-1,4-glycosidic linkages in cellulose. They are members of the glycoside hydrolase families of enzymes that hydrolyse oligosaccharides and/or polysaccharides [23].

Cellulase enzymes perform the major part of cellulose degradation. Cellulases can be produced by a great number of organisms such as plants, plant pathogens and cellulolytic microorganisms, both bacterial and fungal, and have the capability of hydrolyzing highly ordered crystalline cellulose into shorter cellooligomers and glucose [24].

Cellulase, a family of enzymes that breaks down cellulose into glucose molecules, catalyzes the cellulose hydrolysis, ultimately yielding cellobiose and glucose as available carbon and microbial energy sources [14].

Although all cellulolytic enzymes share the same chemical specificity for $\beta$-1,4-glycosidic bonds, they show difference in their specificities towards macroscopic properties of substrate.

Generally, a typical cellulolytic complex includes a variety of hydrolytic and oxidative enzymes such as:

\section{Endoglucanases ( $\beta-1,4-D$ glucanohydrolase,} EC 3.2.1.4

These cellulases play an important role in the cellulose hydrolysis by cleaving cellulose chains randomly and thus encouraging strong degradation [25].

Generally, the indiscriminate action of endoglucanases progressively increases the accessibility of cellulose chain ends, in this manner increasing the specific surface area of the substrate for exocellulase activity.

Endoglucanase attacks the $\beta-1,4$ glycosidic bonds within the amorphous regions of cellulose chains. The products of this attack are oligosaccharides of various lengths and subsequently new chain reducing ends [26].

\section{Exoglucanases ( $\beta$-1,4- D cellobiohydrolase)} EC 3.2.1.91

These degrade crystalline cellulose most efficiently and act in a processive mode on the reducing or non-reducing ends of cellulose polysaccharide chains, releasing either glucose (glucohydrolases) or cellobiose (cellobiohydrolases) as major products [26].

\section{3. $\beta$-glucosidases $(1,4-\beta$-D glucohydrolase) EC}

\subsubsection{1}

These complete the hydrolysis of cellulose. They hydrolyse cellobiose, a potential inhibitor of cellobiohydrolases [27]. The catalytic activity of $\beta$-glucosidase is inversely proportional to the degree of substrate polymerization.

These enzymes can be grouped as aryl $\beta$-Dglucosidases (hydrolysing exclusively aryl- $\beta$ glycosides), cellobiases (hydrolysing diglycosides and cellooligosaccharides) or $\beta$-glucosidases with wide range of substrate specificities [28].

The organization of native cellulose and its hydrolysis by different endoglucanases and cellobiohydrolases is demonstrated schematically in Fig (4)

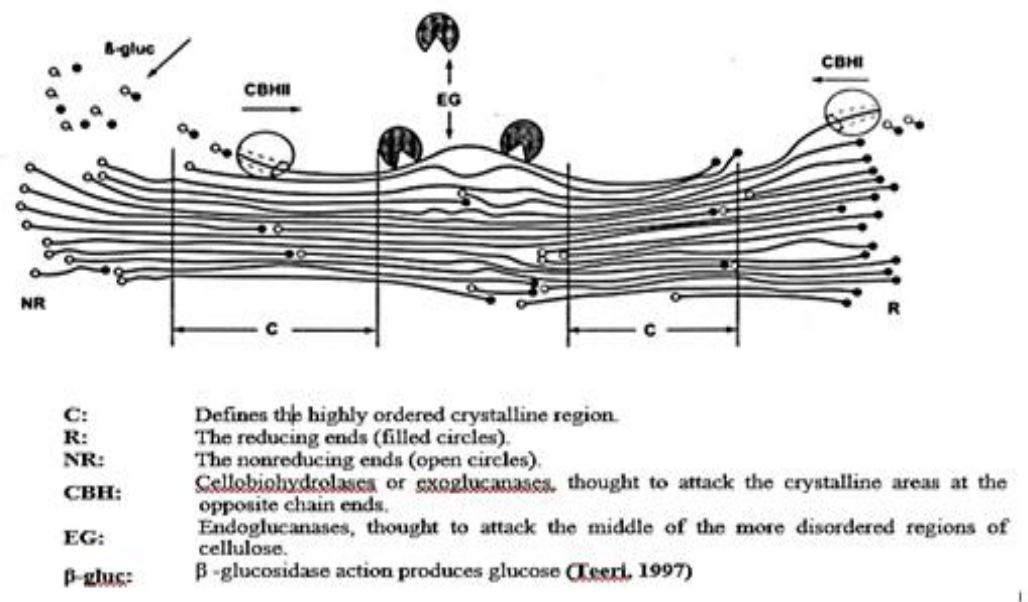

Fig (4) schematic view of the cellulose structure and action of the CBHs, EGs and $\beta$-glucosidases ( $\beta$-gluc)

Cellulases are glycoside hydrolases (GHs) that decompose cellulose, and have a catalytic activity that cleaves the glycosidic bonds and produce polysaccharide substrate [30]. 
Cellulases are distinctly categorized into endoglucanases, exoglucanases and $\beta$-glucosidases (cellobiases) as per their structure and function, but work collaboratively to enforce the hydrolysis of the complex cellulose microfibrils of the plant cell wall.

The endo- and exoglucanases functionally perform the same task, the hydrolysis of glycosidic bonds, but they differ structurally in terms of the site (loop) for cellulose binding [30].

For instance, endoglucanases (E.C.3.2.1.4) are characterized by short loops that can bind to any accessible site (especially the amorphous sites) along cellulose chains to yield long-chain oligomers [31] and [32].

They cause rapid dissociation compared with other cellulases, and their action on cellulose has been identified as the enzyme activity with greatest liquefaction ability that results in a decrease in the chain length and viscosity [33].

Respecting exoglucanases, they have long loops and attract for the crystalline sites along cellulose chains and yield primarily cellodextrin [34]. Exoglucanases are present in two forms, the reducing end (E.C.3.2.1.176) and non-reducing end (E.C.3.2.1.91) [31].

This classification is based on the portion of the oligosaccharide chain each enzyme favorably attacks; however, they work to ensure the breakdown of the polysaccharide [35].

On the other hand, $\beta$-glucosidases possess a rigid structure with active site residing in a large cavity, which favors the entry of disaccharides [36]; even though $\beta$-glucosidases are also capable of hydrolyzing soluble cellodextrins [37].

The active site is encased in four hydrophobic loops with different conformations to enhance substrate binding [36]. $\beta$-glucosidases are classified into two groups A and B. Group (A) includes plant and non-rumen prokaryotic cellobiases, whereas, group (B) includes fungal and rumen bacteria cellobiases [38].

The hydrolysis theory explains that endoglucanases catalyze cellulose chains randomly producing mainly cellodextrin; cellobiohydrolases hydrolyze the crystalline cellulose regions liberating cellobiose as main product; and $\beta$ glucosidases finally hydrolyze the released soluble cello-oligomers to glucose [35].

\subsubsection{Enzymes required for hemicellulose degradation}

Hemicellulose degrading enzymes are hydrolytic, and specifically degrade those glycans that make up the backbone of the hemicelluloses [39]. Typical hemicellulases are therefore endo-1,4$\beta$-D-xylanases that catalyse the random hydrolysis of $\beta-1,4$-glycosidic bonds in xylans.
Xylanases are probably the most widely studied group of hemicellulases in bacteria and fungi due to their numerous biotechnological applications.

The enzymatic degradation of hemicelluloses requires a complex set of different enzymes reflecting the variability of the hemicellulose structure.

Hemicellulose hydrolysis proceeds through the action of endo-type enzymes that liberate shorter fragments of substituted oligosaccharides, which are further degraded by side-group cleaving enzymes and exotype enzymes.

Alternatively, side-branches may be cleaved first. Similarly to cellulose hydrolysis, the hydrolases act synergistically to convert hemicellulose polymer into soluble units [40]. The complex structure of xylan needs different enzymes for its complete hydrolysis.

The depolymerisation action of endo-xylanase results in the conversion of the polymeric substance into xylooligosaccharides and xylose. Endo- $\beta-1,4-$ xylanases that depolymerise xylan by the random hydrolysis of xylan backbone and $\beta-1,4-\mathrm{D}-$ xylosidases which split off small oligosaccharides.

The side groups present in xylan are liberated by $\beta$-L-arabinofuranosidase, $\beta$-Dglucuronidase, galactosidase and acetyl xylan esterase [41]. It is probable that hemicelluloses restrict the access of cellulolytic enzymes by coating cellulose fibers. In some lignocelluloses, pectin could exert a similar effect.

Consequently, enzyme mixtures with similar cellulase activity may show differences in performance on lignocellulose if they differ in hemicellulase composition [42].

A near-theoretical glucose yield (96-104\%) from acid-catalysed steam pretreated corn stover can be obtained if xylanases are used to supplement cellulases during hydrolysis.

Xylanases hydrolyse residual hemicellulose, thereby improving the access of enzymes to cellulose. Under these conditions, xylose yields reached $70-74 \%$. When pre-treatment severity was reduced by using autocatalysis instead of acidcatalysed steam pretreatment, xylose yields were increased to $80-86 \%$. Partial delignification of pretreated material was also evaluated as a way to increase the overall sugar yield.

The overall glucose yield increased slightly due to delignification but the overall xylose yield decreased due to hemicellulose loss in the delignification step [43].

\subsubsection{Enzymes required for lignin degradation}

Lignin is the most recalcitrant to degradation whereas cellulose, because of its highly ordered crystalline structure, is more resistant to hydrolysis than hemicellulose. 
Alkaline and acid hydrolysis methods have been used to degrade lignocellulose. Weak acids tend to remove lignin but result in poor hydrolysis of cellulose whereas strong acid treatment occurs under relatively extreme corrosive conditions of high temperature and $\mathrm{pH}$ which necessitate the use of expensive equipment.

Also, unspecific side reactions occur which yield non-specific by-products other than glucose, promote glucose degradation and therefore reduce its yield.

Some of the unspecific products can be deleterious to subsequent fermentation unless removed. There are also environmental concerns associated with the disposal of spent acid and alkaline.

For lignin degradation, enzymes are preferred than acid or alkaline processes since they are specific biocatalysts, can operate under much milder reaction conditions, do not produce undesirable products and are environmentally friendly [44]. Evidently, other components in pretreated biomass, particularly hemicellulose and lignin, exert significant restraints on cellulose hydrolysis.

For example, one mechanism whereby lignin seems to reduce hydrolytic performance is by binding enzyme components nonproductively. Consequently enzyme mixtures with similar cellulase activity may show differences in performance on lignocellulose if they differ in affinity for lignin [45].

Most cellulolytic microorganisms lack efficient ligninase systems, and cannot or have problems degrading lignin. It is only some basidomycetes (white-rot fungi) that have such efficient systems.
The complex nature of lignin makes its direct degradation by enzymes a difficult task. The degradation of lignin is less well characterized, and there are conflicting opinions on how the different lignin-degrading enzymes act and cooperate [24].

Two families of lignolytic enzymes $\mathbf{F i g}(5)$ are widely considered to play a key role in the enzymatic degradation: (1). Oxidative enzymes (phenol oxidase (laccase) and veratryl alcohol oxidase (VAO)), (2).

Peroxidase enzymes (lignin peroxidase (LiP), versatile peroxidase and manganese peroxidase (MnP)) [46] and [47]. Enzymes involved in lignin breakdown are too large to penetrate the unaltered cell wall of plants so the question arises, how lignases affect lignin biodegradation. Suggestions are that lignases employ low-molecular, diffusible reactive compounds to affect initial changes to the lignin substrate [48].

Laccases are multicopper oxidases that catalyze oxidation of various substituted phenolic compounds, aromatic amines and even certain inorganic compounds by using molecular oxygen as the electron acceptor. Veratryl alcohol oxidase (VAO) enzyme is able to oxidize a number of aromatic alcohols to aldehydes and reduced $\mathrm{O}_{2}$ to $\mathrm{H}_{2} \mathrm{O}_{2}$. The role of the oxidase enzyme in biodegradation might be to produce $\mathrm{H}_{2} \mathrm{O}_{2}$ during oxidation of lignin fragments [22].

The unique capability of white-rot fungi to attack lignified biopolymers has attracted intense research efforts for decades. $P$. sapidus is a member of the oyster mushroom family and secretes a broad set of extracellular enzymes when cultivated on lignified bio-polymers [49].

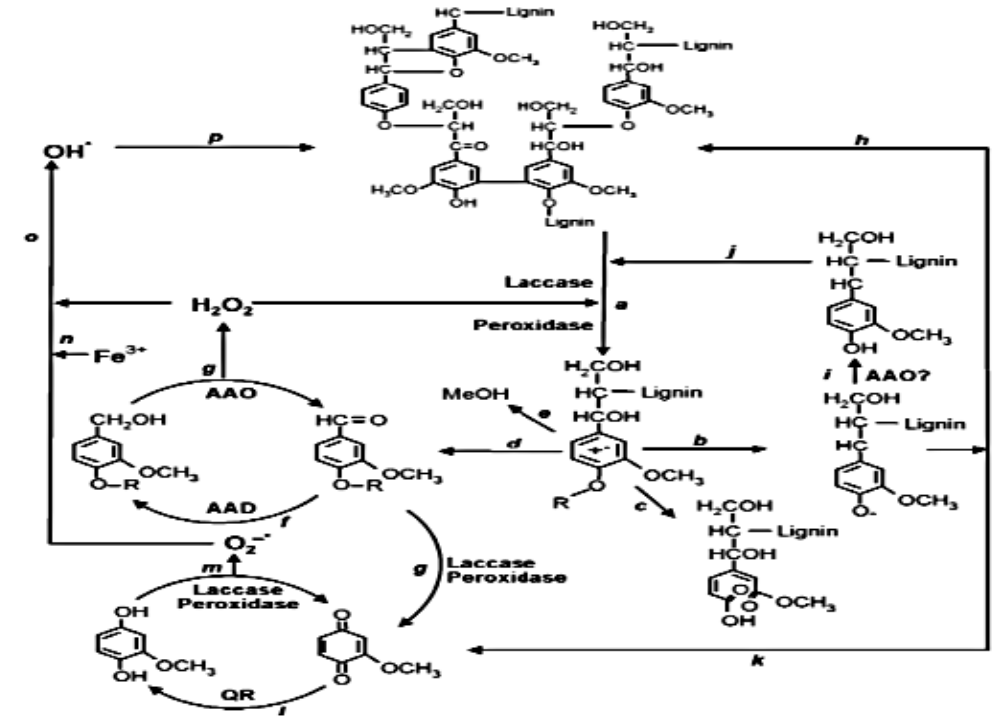

Fig (5) A scheme for lignin biodegradation including enzymatic reactions and oxygen activation

Peroxidases are enzymes that catalyze the oxidation of a variety of organic and some inorganic compounds by hydrogen peroxide and other peroxides. Oxidation of an electron donating substrate by hydrogen peroxide involves the overall transfer of electrons. One electron oxidation of phenols results in the formation of phenoxy radicals, which may diffuse from the enzyme active 
site and undergo a variety of post-enzymatic reactions in aqueous solution [50].

Lignin peroxidase (LiP) and manganese peroxidase $(\mathrm{MnP})$ were described as true ligninases because of their high redox potential. LiP degrades non-phenolic lignin units (up to $90 \%$ of the polymer), whereas MnP generates $\mathrm{Mn}^{3+}$, which acts as a diffusible oxidizer on phenolic or non-phenolic lignin units via lipid peroxidation reactions [51].

More recently, versatile peroxidase (VP) has been described in Pleurotus sp. and other fungi as a third type of ligninolytic peroxidase that combines the catalytic properties of $\mathrm{LiP}, \mathrm{MnP}$, and plant/microbial peroxidases oxidizing phenolic compounds [52].

Versatile peroxidase is glycoproteins with hybrid properties capable of oxidizing typical substrates of MnP and the LiP. VP form an attractive ligninolytic enzyme group due to their dual oxidative ability to oxidize $\mathrm{Mn}^{2+}$ and also phenolic and nonphenolic aromatic compounds. Similar to the MnP mechanism, $\mathrm{Mn}^{3+}$ is released from VP and acts as a diffusible oxidizer of phenolic lignin and free phenol substrates [53].

This is a result of their hybrid molecular structures which provide multiple binding sites for the substrates. This makes VP superior to both LiP and $\mathrm{MnP}$, which are not able to efficiently oxidize phenolic compounds in the absence of VA or oxidize phenols in the absence of $\mathrm{Mn}^{2+}$, respectively [54].

\subsection{Lignocellulase enzymes producing microorganisms}

In nature there are many microorganisms, fungal and bacterial, that produce enzymes that are capable of catalyzing the hydrolysis of cellulose. These microorganisms can be found in plant debris and soil, i.e., where degradation of plant material takes place.

The cellulolytic organisms can be sorted into two different subcategories depending on how the cellulolytic microorganism organizes its enzymes. The first class of cellulolytic microorganisms has cellulolytic enzymes that are organized into multienzyme complexes called cellulosomes.

In these complexes the individual enzyme molecules are anchored onto a common scaffold.

Several different types of enzymes, with different types of catalytic specificity's, e.g., endoglucanases, and cellobiohydrolases CBH. An example of a cellulolytic organism in this class is the bacterium Clostridium thermocellum.

In addition, the second class of cellulolytic organisms produces enzymes that are not attached to one another, and act individually on cellulose. But the different types of enzymes work cooperatively when hydrolyzing cellulose, and by doing this gain strong synergy effects.
Examples of fungi from this class are Trichoderma reesei and Humicola grisea, and of bacteria, Streptomyces lividans and Cellulomonas fimi [55].

In addition, cellulase enzymes production by bacteria with very low activity may indicate that they play a yet unknown role in the breakdown of cellulosic substrates in nature, acting probably as key components of the cellulolytic system of certain cellulase-producing bacteria by means of their synergistic action with other enzymes [56].

There is a large number of microorganisms, including fungi (Trichoderma, Aspergillus, Penicillium, Fusarium, Sclerotium, Schizophyllum, Monilia, etc) and bacteria (Clostridium, Cellulomonas, Pseudomonas, Streptomyces, Actinomycetes, etc), which can form a cellulase enzyme complex.

Among these microorganisms, Trichoderma strains are in the center of attention in enzyme production, because they excrete high amounts of cellobiohydrolyses and endoglucanases, however, their enzyme complex is deficient in the $B$ glucosidase component. In addition, the most common cellulase enzyme is produced by aerobic and mesophilic bacteria.

However, anaerobic, thermophilic bacteria, such as Clostridium thermocellum have also become the subject of research studies recently, partially due to the development of the ethanol production industry [57].

Fungi are the main cellulase-producing microorganisms, although a few bacteria and actinomycetes have also been reported to yield cellulase activity.

Micro-organisms of the genera Trichoderma and Aspergillus are thought to be cellulase producers, and crude enzymes produced by these micro-organisms are commercially available for agricultural use [58]. White-rot fungi were isolated from woodlands in two different temperate regions of Zimbabwe [59].

These are namely the dry, hot region and the wet, cool, humid region. The thermophiles were isolated from Zimbabwean hot water springs. The springs are at temperatures of $65{ }^{\circ} \mathrm{C}, 70{ }^{\circ} \mathrm{C}, 75^{\circ} \mathrm{C}$, $80{ }^{\circ} \mathrm{C}$ and $100{ }^{\circ} \mathrm{C}$ and are located in different regions of the country. All the fungi and bacteria so collected were screened for cellulase, laccase, lignin peroxidase, manganese peroxidase and xylanase activities. From the enzyme activities, it is observed that of the dry, hot region collections, $48.3 \%$ of the microorganisms produced laccase, $70.7 \%$ produced lignin peroxidase, $100 \%$ produced xylanase in extremely low or very high amounts, $24 \%$ produced manganese peroxidase and $98.3 \%$ produced cellulase also in low or high amounts depending on species or strain.

Whereas of the wet, cool region collections, $31.3 \%$ produced laccase, $26.9 \%$ produced lignin 
peroxidase, $99.2 \%$ produced xylanase, $81.3 \%$ produced manganeseperoxidase and $31.3 \%$ produced cellulase.

Of the presumptive thermophiles, $34.3 \%$ produced laccase, $78.1 \%$ produced lignin peroxidase, $100 \%$ produced xylanase, $28.1 \%$ produced manganese peroxidase and $78.1 \%$ produced cellulase. The five enzymes listed here are important lignocellulose biodegrading enzymes for the bioremediation of the pulp and paper industries' effluent water towards decontamination and re-cycling.

White-rot fungi such as Daedalea flavida, Phlebia fascicularia, P. floridensis and P. radiate have been found to selectively degrade lignin in wheat straw and hold out prospects for bioconversion biotechnology were the aim is just to remove the lignin leaving the other components almost intact [60].

In addition, less prolific lignindegraders among bacteria such as those belonging to the genera Cellulomonas, Pseudomonas and the actinomycetes Thermomonospora and Microbispora and bacteria with surface-bound cellulase-complexes such as Clostridium thermocellum and Ruminococcus are beginning to receive attention as representing a gene pool with possible unique lignocellulolytic genes that could be used in lignocellulase engineering. Cellulases and hemicellulases (glycosylhydrolases) are produced by a range of microorganisms, including bacteria, actinomycetes, fungi, and yeast, but fungi appear to be the most efficient producers of extracellular enzymes [61].

The complexity of the enzyme system is increased further by the fact that the microorganisms tend to produce several enzymes within each of the classes. Trichoderma sp. is one of the most well studied producers of cellulases and hemicellulases, produces at least two cellobiohydrolases, five endoglucanases, and three endoxylanases.

A mutant strain Bacillus pumilus (BpCRI6) was isolated for its ability to produce significant amounts of cellulase on agar plates. The isolation was after chemical mutagenesis. The selection of this cellulase-producing strain was based on the diameter of the clear zone surrounding the colonies on the plate-screening medium.

This screening step was found to give fairly reliable indication of exhibited cellulolytic activities. The Bacillus pumilus (BpCRIO) clone and the wild type were further assessed in shaking flask cultures under conditions of catabolite repression [62].

In addition, they mentioned that the enhancement of cellulase production in Bacillus pumilus (BpCRI6) is not due to an increase in cell growth but is only due to the chemical mutagenesis affecting the synthesis of cellulase within the strain.
Carbohydrate utilizing microorganisms living in soil or in animal guts can contribute to close the carbon cycle in the biosphere as a result of the combined action of several extracellular enzymes bearing complementary hydrolytic activities.

Among these enzymes, cellulases and hemicellulases of bacterial or fungal origins play an essential role in vegetal biomass degradation [63].

Cellulase producing fungi were isolated and studied to increase cellulase production using novel mutations. Cellulase-producing fungi were isolated from different soil samples using enriched Mandels cellulose agar, which is a selective media and seven different fungi were selected in the screening programme.

These organisms were tested for cellulase production and two potent strains were identified. Two methods of mutations for strain improvement were employed to these strains.

Hypercellulolytic mutants were selected on the basis of the diameter of the hydrolysis zone surrounding the colonies and used for the fermentation and for checking their cellulase production abilities [64].

They found that, many isolates were able to grow on Mandels medium. Judging from the ratio between the clearing zone diameter and colony diameter, only seven best isolates (CMV1 to CMV7) were chosen for enzyme production studies. CMV1, CMV3, CMV4 were identified as Trichoderma species and CMV2, CMV5, CMV6, CMV7 were identified as Aspergillus species.

Penicillium echinulatum used to produce cellulase and hemicellulases during the solid-state fermentation using a cheap medium containing pretreated sugar cane bagasse and wheat bran [65]. The highest amounts of cellulase and hemicellulases could be measured on mixtures of pretreated sugar cane bagasse and wheat bran.

Nonetheless, few Bacillus and Paenibacillus spp. possess endoglucanases with avicelase activity, a catalytic activity towards the commercial microcrystalline cellulose [66].

A novel thermophilic Paenibacillus sp. strain B39 which produced a high-molecular weight cellulase with both CMCase and avicelase activities. Members of the Paenibacillus genus are facultatively anaerobic organisms, from which many industrial enzymes have been produced widely. In addition, they summarized that strain B39 was closely related to Paenibacillus cookii in 16S rRNA gene sequence.

A cellulase with both CMCase and avicelase activities was secreted from strain B39 and purified by ion-exchange chromatography. By sodium dodecyl sulfate-polyacrylamide gel electrophoresis analysis, the molecular weight of B39 cellulase was also determined [67].

The abovementioned auxiliary enzymes have been commonly sourced from different organisms, 
mainly fungi and bacteria, although plant and animal enzymes are known [68]. Among these organisms, fungi and bacteria express functionally diverse multiple isoforms of cell wall degrading enzymes because of genetic redundancy therefore, fungi and bacteria have become the focus of the recent cellulase industry [69].

The most effective natural cellulolytic enzymes known is obtained from bacteria [70]. Well-known genera for bacteria-based cellulolytic enzymes are mostly Bacillus, Cellulomonas, Streptomyces, Cytophaga, Cellvibrio, and Pseudomonas.

In bacteria, cellulases are mostly present as extracellular aggregated structures attached to the cells [31]. The high protein secretion capacity of Bacillus subtilis, in addition to its high-activity endoglucanase, has also been used to engineer recombinant cellulase strains that thrive on cellulose as a sole carbon source without any other organic nutrient [71].

The Aspergillus species produce different isoforms of enzymes such as cellulases, xylanases, laccases, and other accessory proteins necessary for biomass depolymerization.

Enzymes from Aspergilli are mostly reported to exhibit low total cellulase activity [72]; however, their high $\beta$-glucosidase expressing levels have made them relevant game changers for industrial applications. Interestingly, yeasts have the ability to produce three enzymes for cellulose depolymerization viz. endoglucanase, exoglucanase, and $\beta$-glucosidase [73].

The cellulolytic systems from the genera Clostridium and Thermotoga have contributed to the gradual shift from the dominant fungi sources to that of bacteria.

Cellulases from these species are thermostable and optimally active at elevated temperatures between 60 and $125^{\circ} \mathrm{C}$ thus, making them essential candidates for improving the techno-economics of biomass saccharification. Notably, running enzymatic hydrolysis at higher temperatures has the penchant to increase biomass disorganization and substrate solubility in addition to improve rheological properties and reduce the risk of microbial contamination [33].

More recently, production and characterization of peroxidase enzymes (lignin peroxidase (LiP), manganese peroxidase (MnP) and versatile peroxidase (VP)) from Pleurotus sapidus in the submerged cultivation were studied [74].

It was found that, among four tested media, basal medium containing $1 \%$ rice straw was the best for maximum peroxidases secretion by $P$. sapidus. Wheat straw was the most suitable carbon source for the production of peroxidases.

Concentration of $15 \mathrm{~g} / \mathrm{L}$ of wheat straw was the most suitable for maximum production of LiP and MnP. While, VP showed maximum productivity at $20 \mathrm{~g} / \mathrm{L}$ of wheat straw.
Maximum specific activities of $\mathrm{LiP}$ and $\mathrm{MnP}$ enzymes were at $2 \mathrm{~g} / \mathrm{L}$ of yeast extract. While, concentration of $2.5 \mathrm{~g} / \mathrm{L}$ of yeast extract gave the highest secretion of VP by $P$. sapidus.

The highest specific activities of LiP and VP were obtained after 12 days of incubation. While, MnP reached the maximum specific activity after 3 days of incubation.

Moreover, work deals with optimization the production conditions and characterization of cellulases [Carboxymethyl-cellulase (CMCase), Filter paperase (FPase) and Cellobiase] produced by Gliocladium roseum was achieved [75].

It was emphasized that Reese and Mandel's basal medium was the best for maximum protein and cellulases secretion by $G$. roseum. Maximum protein and cellulases production were found at 15 $\mathrm{g} / \mathrm{L}$ of rice straw and $2 \mathrm{~g} / \mathrm{L}$ yeast extract.

Maximum yield of protein, CMCase and cellobiase were obtained after 6 days of incubation, while maximum yield of FPase was obtained after 4 days of incubation.

Moreover, after enzymes concentration with ultrafiltration, specific activity of CMCase, FPase and cellobiase were 5.14, 2.5 and $3.9 \mathrm{U} / \mathrm{mg}$ protein, respectively.

Optimum temperature for CMCase activity was $55{ }^{\circ} \mathrm{C}$, while $50{ }^{\circ} \mathrm{C}$ was optimum for the activity of FPase and cellobiase. CMCase retained about 55.63 $\%$ of its activity when incubated at $55{ }^{\circ} \mathrm{C}$ for $6 \mathrm{~h}$. While, FPase and cellobiase retained about 15.4 and $14.3 \%$ of the original activity when incubated at $50^{\circ} \mathrm{C}$ for $6 \mathrm{~h}$, respectively.

The optimum $\mathrm{pH}$ for CMCase activity was $\mathrm{pH}$ 4. While $\mathrm{pH} 4.5$ was optimum for the activity of FPase and cellobiase. An isoelectric point around 5.0 was detected for CMCase. The molecular weight was calculated to be about 50KDa.

\subsection{Bioconversion of sugars into biofuel}

Over the years, many technologies have been considered in the quest for low-cost pretreatment approaches that realize high sugars yields from both cellulose and hemicellulose that can be categorized as 1) biological, 2) chemical, 3) physical and 4) thermal processes [8].

Fuel deficiency is a global issue due to exhaustion of fossil fuel and growing climate change [77] and [1]. In order to overcome this issue, different types of techniques have been invented for the possible conversion of cellulosic waste materials into glucose for the ethanol production, as an alternative way for fuel conservation [2].

The bioconversion of lignocellulosic materials (i.e., agricultural residues, woods, and residues from pulp and paper industries, solid wastes) to bioethanol produces high yield of glucose after hydrolysis [78]. The utilization of the 
lignocellulosic materials for the conversion of the biofuel involves only low cost [79].

Lignocellulose, the most abundant organic matter in the Earth, can be utilized to produce various renewable fuels and chemicals [4]. For the digestion of these materials into glucose, many methods have been used such as thermal pretreatments, chemical pretreatments, biological pretreatments and enzymatic pretreatments [5].

Cellulolytic and hemicellulolytic enzymes are able to increase monosugars from the digestion of lignocellulose [6]. For this purpose, fungi in particular Trichoderma species that can produce cellulolytic enzymes are employed [80] and [81].

In general, yeasts are potential microorganisms for the production of bioethanol by sugar fermentation [82] and [83].

However, most of the studies are restricted to microbes of terrestrial origin, but not of marine origin. Hence, the present work was undertaken for the conversion of sawdust (lignocellulosic wastes) to sugars for fuel fermentation using cellulolytic enzymes of the mangrove-derived Trichoderma and further conversion of sugars to bioethanol using the mangrove-derived yeast strain of Saccharomyces cerevisiae. Based on the data, the culture conditions were optimized statistically for the enzyme hydrolysis process and bioethanol fermentation.

The maximum utilization of all sugar fractions is essential to obtain an economic and viable conversion technology for bioethanol production from lignocelluloses.

To obtain the desired ethanol yields from lignocelluloses hydrolysates, it is essential that the hemicellulose fraction should be fermented with same conversion rates as the cellulose fraction. Hemicellulose hydrolysate typically contains primarily pentose sugars (xylose and arabinose) and some amounts of hexose sugars (mannose, glucose and galactose). A variety of yeast, fungi, and bacteria are capable of assimilating pentose, but only a few are promising candidates for the efficient xylose fermentation into ethanol [84].

There are several microorganisms capable of assimilating pentose sugars, but only few species are capable of assimilating sugars to produce ethanol at industrial scale. Microorganisms, such as Schffersomyces stipitis (Pichia stipites, Candida guilliermondii, Candida shehatae and Pachysolen tannophilus are able to assimilate pentose sugars by a reduction/oxidation pathway bioconversion of lignocelluloses hydrolysates under different cultivation conditions [84].

The process to assimilate pentose sugars consists in the xylose being converted to xylitol, by the action of D-xylose reductase and immediately oxidized by the action of xylitol dehydrogenase, producing D-xylose-5-phosphate. Ribolosephosphate-3-epimerase, transaldolas and transketolase sequentially convert D-xylose-5- phosphate intoglyceraldehyde-3-phosphate and fructose-6-phoshateby non-oxidative rearrangement resulting into the formation of ethanol by the Emden-Meyerhof Pathway.

NADPH must be regenerated through metabolic routes. The metabolic pathway of the arabinose is similar to the route shown by xylose, where aldose reductase mechanistically converts arabinose into L-arabitol. Through the action of L-arabitol dehydrogenase, L-arabitol is reduced to ethanol [82].

The yield of ethanol is equivalent to $6,000 \mathrm{~L} /$ hectare planted. It is estimated that ethanol production could reach $10,000 \mathrm{~L} /$ hectare if only half of the Sugarcane bagasse generated is harnessed for the production of biofuel [85].

Bioethanol production using lignocellulosic waste, sawdust and marine yeast fermentation were studied [86]. Lignocellulosic waste materials were converted into monosugars through acid hydrolysis and finally treated with cellulase enzyme derived from Trichoderma sp. and Hypocrea sp.

To enhance the conversion of the glucose from sawdust, the experimental conditions were statistically optimized. The efficient conversion of sawdust to glucose of $78.56 \%$ was achieved under the conditions of $\mathrm{pH} 6.19$, temperature $29{ }^{\circ} \mathrm{C}$, cellulase enzyme $\left(8.16 \mathrm{IU} \mathrm{ml}^{-1}\right)$ and sawdust (7.95 $\mathrm{gl}^{-1}$ ). The lignocellulosic waste-sawdust hydrolysis was used as the carbon source for the production of bioethanol.

Bioethanol production of $85.6 \%$ was achieved $\left(55.2 \mathrm{gl}^{-1}\right)$ under the optimized conditions of temperature of $36.5{ }^{\circ} \mathrm{C}$, incubation time of $102 \mathrm{~h}$ and enzyme-treated sawdust of $45.14 \mathrm{ml} \mathrm{l}^{-1}$ and agitation of $330 \mathrm{rpm}$.

This work achieved maximum bioethanol production using Hansenulla estonica and Saccharomyces cerevisiae fermentation.

The greenhouse gas emissions such as hydrocarbons, sulfur dioxide, carbon dioxide, and nitrogen oxides were reduced when using the bioethanol, blended with fuel because of the highly oxygenated component of bioethanol fuel.

Hence, it is suggested that agricultural waste can be used as a potential feedstock for bioethanol production and appropriate as fuel for engine use.

In this respect, reforming of renewable biomass feedstock such as bioethanol is biodegradable, suitable substitute for fossil fuels, and capable to reduce greenhouse gas, $\mathrm{CO}_{2}$ and NOX, emissions [87].

New feedstock searching is a consequence process of all researchers to enhance the using of bioethanol, suggest the appropriate resources in respect to different geological reason of the world and lead the bioethanol research forward as well.

Date is an important subsistence crop in arid and semiarid regions of the world and an obvious feedstock for liquid bioethanol. In this trend, the 
effects of $\mathrm{pH}$, temperatures, period, substrate concentration, water percent and components of dates on bioethanol production were investigated.

From the results, the optimal yield of bioethanol in the parameters such as $\mathrm{pH}$, temperatures, fermentation period, and yeast concentration was found $8.7 \%$ having $\mathrm{pH} 5.8,28^{\circ} \mathrm{C}, 5$ days using 4 $\mathrm{g} / \mathrm{l}$, respectively.

Viscosity was found under American Society for Testing and Materials (ASTM) standard. The produced bioethanol was analyzed and found that there were no toxic elements and acceptable for transportation fuel and maintained the quality of ASTM standard.

The elements mostly contained in the bioethanol samples were $\mathrm{Fe}, \mathrm{Cu}, \mathrm{Mn}, \mathrm{P}, \mathrm{Ca}, \mathrm{Mg}$ and $\mathrm{Na}$.

\section{References}

[1] M.Sveinsdottir, S.R.B.Baldursson and J.Orlygsson, Ethanol production from monosugars and lignocellulosic biomass by thermophilic bacteria isolated from Icelandic hot springs. Icelandic Agric. Sci., Vol.22, pp.4558, 2009.

[2] Y.Sun and J.Cheng, Hydrolysis of lignocellulosic material from ethanol production: a review. Bioresource Technol., Vol.83, pp.1-11, 2002.

[3] Li.A, B.Antizar-Ladislao and M.Khraisheh, Bioconversion of municipal solid waste to glucose for bioethanol production. Bioprocess Biosyst. Eng., Vol.30(3), pp.189-196, 2007.

[4] M.J.Lau, M.W.Lau, C.Gunawan and B.E.Dale, Ammonia fiber expansion (AFEX) pretreatment, enzymatic hydrolysis and fermentation on empty palm fruit bunch fiber (EPFBF) for cellulosic ethanol production. Appl. Biochem. Biotechnol., Vol.162, pp.18471857, 2010.

[5] M.D.Meinita, Y.K.Hong and G.T. Jeong, Comparison of sulfuric and hydrochloric acids as catalysts in hydrolysis of Kappaphycus alvarezii (cottonii). Bioprocess Biosyst. Eng. J., Vol.35(1-2), p.123, 2012.

[6] A.Pakarinen, J.Zhang, T.Brock, P.Maijala, and L.Viikari, Enzymatic accessibility of fiber hemp is from $\mathrm{GH}$ families 10 and 11 with thermostable cellulases in lignocellulose hydrolysis. Vol.108(12), pp.2823-2834, 2011.

[7] L.J.Jönsson, B.Alriksson, and N.O.Nilvebrant, Bioconversion of lignocellulose: inhibitors and detoxification. Biotechnol. Biofuels, Vol.6(16), pp.1-10, 2013.

[8] C.E.Wyman, B.E.Dale, R.T.Elander, M.Holtzapple, M.R.Ladisch, and Y.Y.Lee, Coordinated development of leading biomass pretreatment technologies. Biores. Technol.,Vol. 96, pp.1959-1966, 2005.

[9] H.Palonen, and A.B.Thomsen, Evaluation of wet oxidation pretreatment for enzymatic hydrolysis of softwood. Appl. Biochem.

Biotechnol., Vol.117(1), pp.1-17, 2004.

[10] T.Kim, and Y.Lee, Pretreatment of corn stover by soaking in aqueous ammonia. Appl. Biochem. Biotechnol., Vol.(121-124), pp.11191131, 2005.

[11] T.Eggeman, and R.T.Elander, Process and economic analysis of pretreatment technologies. Bioresour. Technol., Vol.96, pp.2019-2025, 2005.

[12] M.Zeng, S.M.Nathan, C.P.Huang, M.S.Debra, and M.R.Ladisch, Microscopic examination of changes of plant cell structure in corn stover due to hot water. J. Biotechnol. Bioeng., Vol.97(2), pp.265-278, 2007.

[13] P.Cen, and L.Xia, Production of cellulase by solid-state fermentation. In: Advances in Biochemical Engineering and Biotechnology. Scheper, T. and G. T. Tsao (Eds.). Springer, New York, pp.69-92, 1999.

[14] Dorland's Illustrated Medical Dictionary, W.B. Saunders publications, $30^{\text {th }}$ edition, 2003.

[15] S.B.Leschine, Cellulose degradation in anaerobic environments. Ann. Rev. Microbiol., Vol.49, pp.399-426, 1995.

[16] Q.Gan, S.J.Allen, and G.Taylor, Kinetic dynamics in heterogeneous enzymatic hydrolysis of cellulose: an overview, an experimental study and mathematical modeling. Process Biochemistry, Vol.38(7), pp.1003-1018, 2003.

[17] S.Subramaniyan, and P.Prema, Biotechnology of microbial xylanases: Enzymology, molecular biology and application. Critical reviews in Biotechnol., Vol.22 (1), pp.33-46, 2002.

[18] T.W.Jeffries, Biodegradation of lignincarbohydrate complexes. Biodegradation, Vol.1, pp.163-176, 1990.

[19] R.H.Atalla, J.M.Hackney, I.S.Uhlin, and N.S.Thompson, Hemicelluloses as structure regulators in the aggregation of native cellulose. Int. J. Biol. Macromol., Vol.15, pp.109-112, 1993.

[20] S.Bissoon, L.Christov and S.Singh, Bleach boosting effects of purified xylanase from Thermomyces lanuginosus SSBP on bagasse pulp, Process Biochem., Vol.37, pp.567-573, 2002.

[21] R.H.Atalla, Cellulose and the hemicelluloses: patterns for cell wall architecture and the assembly of lignin. Proceedings of the $8^{\text {th }}$ Int. Symp. on Wood and Pulping Chem., Vol.1, pp.77-84, 1995.

[22] R.Bourbonnais, M.G.Paice, B.Freiermuth, E.Bodie and S.Borneman, Reactivities of various mediators and laccases with kraft pulp and lignin model compounds. Appl. Environ. Microbiol.,Vol.63, pp.27-32, 1997.

[23] W.H.Schwarz, The cellulosome and cellulose degradation by anaerobic bacteria. A mini- 
review. Appl. Microbiol. Biotechnol., Vol.56, pp.634-649, 2001.

[24] M.Sandgren, Structural and functional studies of glycoside hydrolase family 12 enzymes from Trichoderma reesei and other cellulolytic microorganisms. Ph.D. Thesis, Faculty of Science, Uppsala University, Sweden, 2003.

[25] Y.Cao and T.Huimin, Effects of cellulase on the modification of cellulose. Carbohydrate Research., Vol.337, pp.1291-1296, 2002.

[26] L.R.Lynd, P.J.Weimer, W.H.Vanzyl, and I.S.Pretorius, Microbial cellulose utilization: Fundamentals and biotechnology. Microbiol. Mole. Boil. Rev., Vol.66(3), pp.506-577, 2002.

[27] M.A.Lemos, J.A.Teixeira, M.R.M.Domingues, M.Mota and F.M. Gama, The enhancement of the cellulolytic activity of cellobiohydrolases I and endoglucanase by the addition of cellulose binding domains derived from Trichoderma reesei. Enzy. Micro. Technol., Vol.32, pp.3540, 2003.

[28] M.K.Bhat and G.P.Hazlewood, Enzymology and other characteristics of cellulases and xylanases. In: Enzymes in farm animal nutrition. Bedford, M.R. and Patridge, G.G. (Eds.). CAB International, pp.11-60, 2001.

[29] M.Garvey, H.Klose, R.Fischer, et al. Cellulases for biomass degradation: comparing recombinant cellulase expression platforms. Trends Biotechnol., Vol.31, pp.581-593, 2013.

[30] V.Juturu and J.C.Wu, Microbial cellulases: engineering, production and applications. Renew Sustain Energy Rev., Vol.33, pp.188203, 2014.

[31] K.Wilson, Biomolecular interactions: In: Practical biochemistry, principles and techniques. (eds Wilson, K. and Walker, J.). Fifth edition. Cambridge University Press. P.373, 2000.

[32] A.Boyce and G.Walsh, Characterization of a novel thermostable endoglucanase from Alicyclobacillus vulcanalis of potential application in bioethanol production. Appl. Microbiol. Biotechnol., Vol.99, pp.7515-7525, 2015.

[33] F.Segato, A.R.L.Damsio, and R.C.de Lucas, Genome analyses highlight the different biological roles of cellulases. Microbiol. Mol. Biol. Rev., Vol.78, pp.588-613, 2014.

[34] R.Wahlström, J.Rahikainen, K.Kruus, and A.Suurnnkki, Cellulose hydrolysis and binding with Trichoderma reesei Cel5A and Cel7A and their core domains in ionic liquid solutions. Biotechnol. Bioeng., Vol.111, pp.726-733, 2014.

[35] K.H.Nam, M.W.Sung, and K.Y.Hwang, Structural insights into the substrate recognition properties of $\beta$-glucosidase. Biochem. Biophys. Res. Commun., Vol.391, pp.1131-1135, 2010.
[36] Y.H.P.Zhang and L.R.Lynd, Toward an aggregated understanding of enzymatic hydrolysis of cellulose: noncomplexed cellulase systems. Biotechnol. Bioeng., Vol.88, pp.797824, 2004.

[37] M.Park, Q.Sun, and F.Liu, Positional assembly of enzymes on bacterial outer membrane vesicles for cascade reactions. PLOS ONE Vol.9, pp.1-6, 2014.

[38] L.Viikari, A.Kantelinen, J.Sundquist, and M.Linko, Xylanases in bleaching: from an idea to the industry. FEMS Microbiol., Vol.13, pp.335-350, 1994.

[39] M.Tenkanen, M.Siika-Aho, T.Hausalo, J.Puls, and L.Viikari, Synergism of xylanolytic enzymes of Trichoderma reesei in the degradation of acetyl-4-Omethylglucuronoxylan. In: Srebotnik, E. \& Messner, K. (Eds.): Proceedings of the $6^{\text {th }}$ International Conference on Biotechnology in the Pulp and Paper Industry: Adv. Appl. Fund. Res., Facultas-Universitätsverlag, Vienna, Austria, pp.503-508, 1996.

[40] S.Subramaniyan, and P.Prema Biotechnology of microbial xylanases: Enzymology, molecular biology and application. Critical reviews in Biotechnol., Vol.22 (1), pp.33-46, 2002.

[41] A.Berlin, N.Gilkes, D.Kilburn, V.Maximenko, R.Bura, A.Markov, A.Skomarovsky, O.Okunev, A.Gusakov, D.Gregg, A.Sinitsyn, and J.Saddler, Evaluation of cellulase preparations for hydrolysis of hardwood substrates. Appl. Biochem. Biotechnol., 129-132 and 528-545, 2006.

[42] K.Ohgrena, R.Burab, J.Saddlerb, and G.Zacchi, Effect of hemicellulose and lignin removal on enzymatic hydrolysis of steam pretreated corn stover. Bioresource. Technol., Vol.98(13), pp.2503 -2510, 2007.

[43] R.L.Howard, E.Abotsi, E.L.Jansen van Rensburg, and S.Howard, Lignocellulose biotechnology: issues of bioconversion and enzyme production. Afr. J. Biotechnol., Vol.2(12), pp.602-619, 2003.

[44] A.Berlin, V.Maximenko, N.Gilkes, and J.Saddler, Optimization of enzyme complexes for lignocellulose hydrolysis. Biotechnology and Bioengineering, Vol.97(2), pp.287-296, 2007.

[45] D.O.Krause, S.E.Denman and R.I.Mackie, Opportunities to improve fiber degradation in the rumen. Microbiology, Ecology, and Genomics. FEMS Microbiol. Rev., Vol.797, pp.1-31, 2003.

[46] S.Malherbe, and T.E.Cloete, Lignocellulose biodegradation: fundamentals and applications: A review. Environ. Sci. Biotechnol., Vol.1, pp.105-114, 2003.

[47] H.P.Call, and I.Mücke, History, overview and applications of mediated lignolytic systems, 
especially laccase-mediator-systems (Lignozyme $^{\circledR}$-process). J. Biotechnol., Vol.53, pp.163-202, 1997.

[48] M.Matis, M.Z.Mavric, and J.P.Katalinic, Mass spectrometry and database search in the analysis of proteins from the fungus Pleurotus ostreatus. Proteomics, Vol.5, pp.67-75, 2005.

[49] B.W.Griffin, Chloroperoxidase: a review. In: Peroxidases in Chemistry and Biology (Eds.) Everse, J.; Everse, K.E. and Grisham, M.B.), 2:85-137. CRC Press, Boca Raton, Fla, 1991.

[50] A.T.Martinez, M.Speranza, F.J.Ruiz-Duenas, P.Ferreira, S.Camarero, F.Guillen, M.J.Martinez, A.Gutierrez and J.C.del Rio, Biodegradation of lignocellulosics: microbial, chemical, and enzymatic aspects of the fungal attack of lignin. Int. Microbiol., Vol.8, pp.195204, 2005.

[51] A.Heinfling, F.J.Ruiz-Duenas, M.J.Martinez, M.Bergbauer, U.Szewzyk, and A.T.Martinez, A study on reducing substrates of manganeseoxidizing peroxidases from Pleurotus eryngii and Bjerkandera adusta. FEBS Lett., Vol.428, pp.141-146, 1998.

[52] D.Wesenberg, I.Kyriakides, and S.N.Agathos, White-rot fungi and their enzymes for the treatment of industrial dye effluents. Biotechnol. Adv.; Vol.22, pp.161-187, 2003.

[53] F.JRuiz-Duenas, M.Morales, E.Garcia, Y.Miki, M.J.Martinez, and A.T.Martinez, Substrate oxidation sites in versatile peroxidase and other basidiomycete peroxidases. J. Exp. Bot., Vol.60, pp.441-452, 2009.

[54] E.A.Bayer, H.Chanzy, R.Lamed, and Y.Shoham, Cellulose, cellulases and cellulosomes. Curr. Opin. Struct. Biol., Vol.8, pp.548-557, 1998.

[55] S.Zhang, D.C.Irwin, and D.B.Wilson, Sitedirected mutation of noncatalytic residues of Thermobifida fusca exocellulase Cel6B. Eur. J. Biochem., Vol.267,pp.3101-3115, 2000.

[56] M.Bollok, and K.Reczey, Cellulase enzyme production by various fungal strains on different carbon sources. Acta Alimentaria, Vol.29(2), pp.155-168, 2000.

[57] Z.Szengyel, G.Zacchi, A.Varga, and K.Reczey, Cellulase production of Trichoderma reesei RUT C30 using steam-pretreated spruce. Hydrolytic potential of cellulases on different substrate. Appl. Biochem. Biotechnol., Vol.84(86), pp.679-691, 2000.

[58] C.C.Muzariri, J.Mapingire, J.Mazorodze and L.Mandikutse, Isolation and screening of microorganisms for potential application in remediation of effluent water from the pulp and paper industry $2^{\text {nd }}$ WARFSA/WaterNet Symposium: Integrated Water Resources Management: Theory, Practice, Cases; Cape Town, pp.30-31, 2001 .
[59] D.S.Arora, M.Chander, and P.K.Gill, Involvement of lignin peroxidase, manganese peroxidase and laccase in the degradation and selective ligninolysis of wheat straw. Int. Bioterior. Biodegrad., Vol.50, pp.115-120, 2002.

[60] H.Jorgensen, T.Erriksson, and J.Borjesson, Purification and characterization of five cellulases and one xylanases from Penicillium brasilianum IBT 20888. Enzyme Microb. Technol., Vol.32, pp.851-861, 2003.

[61] O.S.Kotchoni, O.O.Shonukan, and W.E.Gachomo, Bacillus pumilus BpCRI 6, a promising candidate for cellulase production under conditions of catabolite repression. Afr. J. Biotechnol., Vol.2(6), pp.140-146, 2003.

[62] K.Murashima, A.Kosugi, and R.H.Doi, Synergistic effects of cellulosomal xylanase and cellulases from Clostridium cellulovorans on plant cell wall degradation. J. Bacteriol., Vol.185, pp.1518-1524, 2003.

[63] P.Chand, A.Aruna, A.M.Maqsood, and L.V.Rao, Novel mutation method for increased cellulase production. J. Appl. Microbiol., Vol.98, pp.318-323, 2005.

[64] M.Camassola, and A.J.P.Dillon, Production of cellulases and hemicellulases by Penicillium echinulatum grown on pretreated sugar cane bagasse and wheat bran in solid-state fermentation. J. Appl. Microbiol., Vol.103, pp.2196-2204, 2007.

[65] A.Ogawa, A.Suzumatsu, S.Takizawa, H.Kubota, K.Sawada, Y.Hakamada, S.Kawai, and T.Kobayashi, Endoglucanases from Paenibacillus spp. from a new clan in glycoside hydrolase family. J. Biotechnol., Vol.129, pp.406-414, 2007.

[66] C.M.Wang, C.L.Shyu, S.P.Ho, and S.H.Chiou, Characterization of a novel thermophilic, cellulose degrading bacterium Paenibacillus sp. strain B39. Lett. Appl. Microbiol., pp.02668254, 2008.

[67] S.Kim, and C.H.Kim, Production of cellulase enzymes during the solid-state fermentation of empty palm fruit bunch fiber. Bioprocess Biosyst. Eng., Vol.35, pp.61-67, 2012.

[68] A.K.Badhan, B.S.Chadha, J.Kaur, et al., Production of multiple xylanolytic and cellulolytic enzymes by thermophilic fungus Myceliophthora sp. IMI 387099. Bioresour. Technol., Vol.98, pp.504-510, 2007.

[69] J.Stern, A.Kahn, and Y.Vazana, Significance of relative position of cellulases in designer cellulosomes for optimized cellulolysis. PLOS ONE 10:e0127326, 2015.

[70] Y.H.P.Zhang, Substrate channeling and enzyme complexes for biotechnological applications. Biotechnol. Adv., Vol.29, pp.715$725,2011$. 
[71] D.L.Falkoski, V.M.Guimares, de M.N.Almeida, et al.; Chrysoporthe cubensis: a new source of cellulases and hemicellulases to application in biomass saccharification processes. Bioresour. Technol., Vol.130, pp.296-305, 2013.

[72] Y.Matano, T.Hasunuma, and A.Kondo, Cell recycle batch fermentation of high-solid lignocellulose using a recombinant cellulasedisplaying yeast strain for high yield ethanol production in consolidated bioprocessing. Bioresour. Technol., Vol.135, pp.403-409, 2013.

[73] V.Parisutham, T.H.Kim, and S.K.Lee, Feasibilities of consolidated bioprocessing microbes: from pretreatment to biofuel production. Bioresour. Technol., Vol.161, pp.431-440, 2014.

[74] A.A.Salem, Peroxidase enzymes of Pleurotus sapidus, production and characterization. Annals of Agric. Sci., Moshtohor, Vol.53(1), pp.25-32, 2015.

[75] A.A.Salem and H.M.Abdel Rahman, Optimization and characterization of cellulolytic enzymes produced from Gliocladium roseum. J. Agric.Chem.and Biotechn., Mansoura Univ.Vol.6 (11), pp. 473 - 488, 2015.

[76] A.Wingren, M.Galbe, G.Zacchi, Technoeconomic evaluation of producing ethanol from softwood: comparison of SSF and SHF and identification of bottlenecks. Biotechnol. Prog., Vol.19, pp.1109-1117, 2003.

[77] J.D.McMillan, Bioethanol production: status and prospects. Renewable Energy, Vol.10, pp.295-302, 1997.

[78] D.Li, X.Li, W.Dang, et al.; Characterization and application of an acidophilic and thermostable $\beta$-glucosidase from Thermofilum pendens. J. Biosci. Bioeng., Vol.115, pp.490496, 2013.

[79] N.Aro, T.Pakula, and M.Penttiillae, Transcriptional regulation of plant cell wall degradation by filamentous fungi. FEMS

Microbiol. Rev., Vol.29, pp.719-739, 2005.

[80] G.Rodriguez, D.Lehmann, L.Olkjar et al.; Examining the potential of plasma-assisted pretreated wheat straw for enzyme production by Trichoderma reesei. Appl. Biochem. Biotechnol. 166(8):2051-2063 (Data provider: Technical University of Denmark Document type), 2012.

[81] K.Kathiresan, K.Saravanakumar, and P.Senthilraja, Bio-ethanol production by marine yeasts isolated from coastal mangrove sediment. Int. Multidiscip. Res. J., Vol.1(1), pp.19-24, 2011.

[82] P.Senthilraja, K.Kathiresan, and K.Saravanakumar, Comparative analysis of bioethanol production by different strains of immobilized marine yeast. J. Yeast Fungal Res., Vol.2(8), pp.113-116, 2011.

[83] S.P.Singh, and D.Singh, Biodiesel production through the use of different sources and characterization of oils and their esters as the substitute of diesel: a review. Renewable Sus. Energy Rev., Vol.14(1), pp.200-216, 2010.

[84] L.Canilha, A.K.Chandel, T.S.S.Milessi, F.A.F.Antunes, W.L.C.Freitas, M.G.A.Felipe, and S.S.Silva, Bioconversion of Sugarcane Biomass into Ethanol: An Over view about Composition, Pretreatment Methods, Detoxification of Hydrolysates, Enzymatic Saccharification, and Ethanol Fermentation. J. Biomedicine Biotechnol., pp.1-15, 2012.

[85] K.Saravanakumar, and K.Kathiresan, Bioconversion of lignocellulosic waste to bioethanol by Trichoderma and yeast fermentation. Biotech., Vol.4, pp.493-499, 2014.

[86] S.Hossain, V.N.Veettil, E.A.Sulieman, and R.Kamaludin, Bioethanol fuel production from date waste as Renewable energy. Adv. Biores., Vol.7(2), pp.137-142, 2016. 